\title{
Dinitrosyl rhenium complexes for ring-opening metathesis polymerization (ROMP)*
}

\author{
Christian Manfred Frech, Olivier Blacque, and Heinz Berke \\ Department of Inorganic Chemistry, University of Zurich, 8057 Zurich, Switzerland
}

\begin{abstract}
The treatment of benzene solutions of the cations $\left[\mathrm{Re}(\mathrm{NO})_{2}\left(\mathrm{PR}_{3}\right)_{2}\right]\left[\mathrm{BAr}^{\mathrm{F}}{ }_{4}\right](\mathrm{R}=$ $\mathrm{Cy}$ and $\mathrm{R}={ }^{i} \operatorname{Pr} ;\left[\mathrm{BAr}_{4}{ }_{4}\right]=$ tetrakis $\{3,5$-bis(trifluoromethyl)phenyl $\}$ borate) with phenyldiazomethane afforded the moderately stable cationic rhenium(I) benzylidene dinitrosyl bis(trialkyl) phosphine complexes as $\left[\mathrm{BAr}_{4}{ }_{4}\right]^{-}$salts in good yields. The cationic rhenium dinitrosyl bisphosphine complexes catalyze the ring-opening metathesis polymerization (ROMP) of highly strained nonfunctionalized cyclic olefins to give polymers with relatively high polydispersity indices, high molecular weights, and $Z$ configurations of the double bonds in the polymer chain backbones of over $80 \%$. The benzylidene derivatives are almost inactive in ROMP catalysis with norbornene and in olefin metathesis. NMR experiments gave first hints for the initial formation of carbene complexes when $\left[\mathrm{Re}(\mathrm{NO})_{2}\left(\mathrm{PR}_{3}\right)_{2}\right]\left[\mathrm{BAr}{ }_{4}\right]$ was treated with norbornene. The carbene formation is initiated by an unique reaction sequence where the cleavage of the strained olefinic bond starts with phosphine migration forming a cyclic ylid carbene complex. The [2+2] addition of a norbornene molecule to the $\mathrm{Re}=\mathrm{C}$ bond leads to the rhenacyclobutane complex, which is expected to be converted into an iminate complex by attack of the ylid function onto one of the $\mathrm{N}_{\mathrm{NO}}$ atoms followed by Wittig-type phosphine oxide elimination. The formation of phosphine oxide was confirmed by NMR spectroscopy. This species is thought to drive the ROMP metathesis with alternating rhenacyclobutane formations and cycloreversions. The proposed mechanism is supported by density functional theory (DFT) calculations.
\end{abstract}

Keywords: ring-opening metathesis polymerization; rhenium; (pre)catalyst; initiation mechanism; density functional theory calculations.

\section{INTRODUCTION}

The transition-metal-catalyzed olefin metathesis allows the transformation of olefins into new ones with exchange of the olefinic carbene units (Scheme 1) [1-4]. This reaction was discovered in the late 1950s by Herbert S. Eleuterio, at DuPont's petrochemicals department, in Delaware, USA, on investigations with propene over heterogeneous molybdenum catalysts and initiated widespread studies of this field in industry as well as in academic institutions [5]. Hence, shortly thereafter a number of very active homogeneous catalysts have been discovered and described [6-9]. The large majority of these catalysts contained molybdenum or tungsten centers in high oxidation states. Low-valent nitrosyl derivatives of molybdenum have also been successfully used [9].

\footnotetext{
*Paper based on a presentation at the $15^{\text {th }}$ International Symposium on Fine Chemistry and Functional Polymers (FCFP-XV) and the $1^{\text {st }}$ International Symposium on Novel Materials and their Synthesis (NMS-I), 17-20 October 2005, Shanghai, China. Other presentations are published in this issue, pp. 1803-1896.

$\ddagger$ Corresponding author
} 


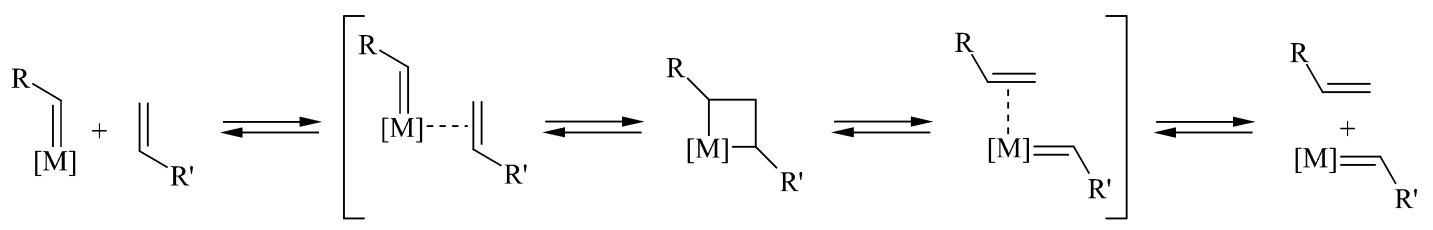

Scheme 1

Rhenium-based heterogeneous catalysts were discovered in 1965 and are typically prepared by impregnating $\gamma-\mathrm{Al}_{2} \mathrm{O}_{3}$ with aqueous solutions of $\mathrm{NH}_{4} \mathrm{ReO}_{4}$ or $\mathrm{HReO}_{4}$ followed by drying and calcination steps. These systems still belong to the most active heterogeneous catalysts. Moreover, these catalysts, also referred to as $\mathrm{Re}_{2} \mathrm{O}_{7} / \mathrm{Al}_{2} \mathrm{O}_{3}$, show very high selectivity at low temperatures (273-373 K) as well as tolerate functionalized olefins especially when this system is activated with organotin agents and, hence, have major advantages compared with the molybdenum- or tungsten-based systems [10]. Unfortunately, the structure of the catalytic active species is unknown. The first homogeneous rhenium catalysts were reported in the early 1970s and also contain the metal center in high oxidation states [7,9]. Typically, its halide derivatives were used as precursors, which were activated with organometallic compounds. The $\mathrm{ReCl}_{5} /\left(n-\mathrm{C}_{4} \mathrm{H}_{9}\right)_{4} \mathrm{Sn}$ system is active at room temperature, but extended times $(46 \mathrm{~h})$ are required to reach equilibrium conversions [11]. Triphenylphosphine complexes of $\mathrm{ReC}_{4}$ and $\mathrm{ReOX}_{3}(\mathrm{X}=\mathrm{C} 1, \mathrm{Br})$ are also active in homogeneous systems at room temperature or even below [12]. Both catalysts require the synergistic use of alkylaluminum cocatalysts. The $\mathrm{ReCl}_{5} /\left(\mathrm{C}_{2} \mathrm{H}_{5}\right)_{3} \mathrm{Al}$ system is not active in metathesis by itself, but becomes active in the presence of catalytic amounts of oxygen [13]. The system is relatively long-lived and is active at room temperature. Another interesting example is methyltrioxorhenium (MTO). MTO is an excellent catalyst for a wide range of reactions. One of these is the olefin metathesis $[14,15]$. Remarkably, no cocatalyst is required, and even functionalized olefins can be transformed. Mechanistic studies performed with UV photoconversion in an argon matrix provided the formation of the methylene hydroxy derivative of MTO as a potentially catalytic active system [16]. Rare examples, where the metal center is in a low oxidation state, are known. One of these systems is the mononuclear carbonyl derivative $\operatorname{Re}_{2}(\mathrm{CO})_{10}$, which is active at high temperature $\left(160{ }^{\circ} \mathrm{C}\right)$ in the presence of alkylaluminum halides [17]. Other examples are the anionic and dinuclear, metal-metal bond-containing systems of the type $\mathrm{A}\left[(\mathrm{CO})_{5} \mathrm{M}-\mathrm{M}^{\prime}(\mathrm{CO})_{5}\right]$ (where $\mathrm{A}$ is an alkali metal or tetraalkylammonium ion, $\mathrm{M}$ is $\mathrm{Mo}$ or $\mathrm{W}$, and $\mathrm{M}^{\prime}$ is $\mathrm{Mn}$ or Re). These dinuclear systems show catalytic activity when cocatalysts are present. The Re derivatives were found to be far more effective in promoting olefin metathesis than the corresponding Mn complexes [18,19]. Although direct evidence of the formation of coordinated carbene units was observed when $\operatorname{Re}(\mathrm{CO})_{5}$ was activated with $\mathrm{C}_{2} \mathrm{H}_{5} \mathrm{AlCl}_{2}$, in all these cases, the nature of the catalytically active species is unknown.

However, since the beginning of the discovery of the olefin metathesis, a variety of applications, such as ring-opening metathesis (ROM), ring-opening metathesis polymerization (ROMP), ring-closing metathesis (RCM), cross-metathesis (CM), and acyclic diene-metathesis polymerization (ADMET) have been developed, making this transformation to the most widely used $\mathrm{C}-\mathrm{C}$ bond-forming reaction. Examples for industrial processes where the olefin metathesis is involved are the large-scale production of long-chain $\alpha$-olefins [20] by the Shell higher olefin process (SHOP), ROMP, and their commercialization by B. F. Goodrich (Telene) and Hercules (Metton) for reaction-injection molding [21] (RIM), and CDF-Chimie (Norsorex) and Degussa-Hüls (Vestenemer) for specialty resins. Since the well-defined late transition-metal alkylidene complexes were introduced, the metathesis reaction became more and more important for synthetic applications and is currently an indispensable tool in organic synthesis. Particularly, the ruthenium-based complexes with the general formula [ $\left(\mathrm{PR}_{3}\right)_{2} \mathrm{Cl}{ }_{2} \mathrm{Ru}$ (carbene) $]$ [20-23] have significantly broadened the scope of the reaction due to their high activity and excellent tolerance to many common functional groups [24]. Replacement of one phosphine ligand by a $\mathrm{N}$-heterocyclic carbene [25] has led to a new class of metathesis catalysts [26-28], which display higher 
phenomenological activity than the original Grubbs complexes, even approaching the activities of the very active molybdenum catalysts, $\left[\mathrm{Mo}(=\mathrm{CHR})(\mathrm{OR})_{2}(\mathrm{NAr})\right][29]$ developed by Schrock. Ruthenium carbene complexes with chelating bis(phosphane) ligands, and hence cis stereochemistry, also act as catalysts for olefin metathesis, particularly in their cationic forms [30]. Recently, Piers et al. published a fast initiating 14-electron ruthenium-based catalyst closely related to the Grubbs systems [31].

The mechanistic understanding of the olefin metathesis was an affair of a long discussion in the chemical community of homogeneous catalysis and organometallic chemistry. The now generally accepted mechanism for the olefin metathesis reaction was proposed by Chauvin [32] and consists of a sequence of formal [2+2] cycloadditions and cycloreversions involving alkenes, metal carbenes, and metallacyclobutane intermediates. The initial reaction step is the olefin coordination to the transitionmetal carbene complex to form a $\pi$-complex. The following migratory insertion of the olefin ligand into the metal-carbene bond leads to a metallacyclobutane complex. The cleavage of two different bonds in the metallacyclobutane, forming another $\pi$-complex, is followed by a dissociation to give the products (see Scheme 1).

All individual steps of the catalytic cycle are reversible, and therefore it is important to shift the equilibrium in one direction in order to make metathesis productive in preparative terms. Although the general mechanistic features are accepted, the detailed pathway of the metathesis reactions depends on the chosen catalyst. Therefore, the mechanistic details of the olefin metathesis reaction catalyzed by ruthenium carbene complexes have been the subject of intense experimental studies to explore the parameters with the strongest influence for the activity of the particular catalysts [33-43]. These studies included systematic kinetic measurements in solution [26-33] as well as electrospray ionization tandem mass spectrometry (ESI-MS/MS) [38-41] in the gas phase and characterizations of model complexes for catalytic intermediates by X-ray diffraction studies [30c,42,43]. These investigations have resolved a number of mechanistic questions, and it turns out that the ligands of the Grubbs-type complexes have significant impact on initiation rates and on catalyst activities in reactions of different substrates in solution [37]. Although there is quite a number of efficient catalysts known, screening is still highly desirable with regard to the type of metal center involved $[41,44,45]$.

Although heterogeneous systems are commercially used in a much larger scale than the homogeneous competitors, only little improvement has been achieved in their synthesis and performance compared with the homogeneous systems. The most important reason for these little improvements of the heterogeneous systems is the low content of active sites (typically less than $2 \%$ ), [46] coupled with their diversity. This makes it very difficult to characterize the catalytic active centers and hence to obtain structure-activity relationships [47]. Hence, their initiation mechanisms as well as the structures of the catalytic active centers are still unknown. Remarkably, in contrast to the most important homogeneous catalysts based on molybdenum and ruthenium metals, defined soluble rhenium complexes with high oxidation state(s), as it is anticipated as the active centers in the heterogeneous rhenium-based catalysts, have rarely been found to show high activity, as already mentioned above. A few catalysts are known with rhenium in high oxidation state [48], while systems with rhenium in low oxidation state were not studied yet, with the exception of dinuclear rhenium carbonyl complexes activated with cocatalysts $[49,50]$.

Therefore, our interest was focused on the development of novel rhenium-based olefin metathesis catalysts wishing to combine with this metal center the high activity of the homogeneous molybdenum catalysts and the excellent property of the ruthenium systems to be tolerant to most of the common functional groups. Our explorations on well-defined $\left[\operatorname{Re}(\mathrm{NO})_{2}(\text { phosphine })_{2}\right]^{+}$cations [51] for use in metathesis catalysis were first of all triggered by the mentioned lack of investigations on homogeneous rhenium-based systems in low oxidation states. Furthermore, the high activity of the isoelectronic dinitrosyl molybdenum and tungsten complexes [9,52], for which, however, the actual catalytically active species is not yet reliably established, also supported our approach. 


\section{ROMP catalysis of $\left[\operatorname{Re}(\mathrm{NO})_{2}\left(\mathrm{PR}_{3}\right)_{2}\right]^{+}$cations}

The treatment of benzene solutions of the cations $\left[\operatorname{Re}(\mathrm{NO})_{2}\left(\mathrm{PR}_{3}\right)_{2}\right]\left[\mathrm{BAr}_{4}\right]\left(\mathrm{R}=\mathrm{PCy}_{3} \mathbf{1 a}\right.$ and $\mathrm{R}=\mathrm{P}^{i} \mathrm{Pr}_{3}$ 1b) with phenyldiazomethane led to the benzylidene complexes $\left[\mathrm{Re}(=\mathrm{CHPh})(\mathrm{NO})_{2}\left(\mathrm{PR}_{3}\right)_{2}\right]^{+}\left[\mathrm{BAr}_{4} \mathrm{~F}_{4}\right]$ (2a and 2b) in high yields (see Scheme 2) [53].<smiles>[R17][R]([R17])([NH-])[I-][I+]C</smiles>

$1 \mathbf{a}, \mathbf{b}$

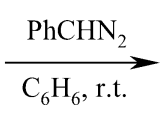

$\mathrm{R}=\mathrm{Cy} \mathbf{a} ; \mathrm{R}={ }^{i} \operatorname{Pr} \mathbf{b}$
$\left[\mathrm{BAr}_{4}^{\mathrm{F}}\right]^{-}$

\section{$\left[\mathrm{BAr}_{4}^{\mathrm{F}}\right]^{-}$}

Scheme 2

The benzylidene complexes $\mathbf{2 a}$ and $\mathbf{2 b}$ were tested in ROMP catalysis with norbornene, but catalytic activity could not be observed. However, when $0.1-0.2 \mathrm{~mol} \%$ of $\mathbf{1 a}$ and $\mathbf{1 b}$ were added to norbornene, dicyclopentadiene (DCPD) or cyclooctene-containing chlorobenzene solutions at room temperature, the formation of polymers was observed with high molecular weight (up to $2.191 \times 10^{6} M_{\mathrm{n}}$ ) and a high $Z$ content $(>80 \%)$ of the olefin groups in the polymer chain backbone. Turnover frequencies of up to 700 were calculated (see Table 1). Since catalytic metathesis activity was observed for 1a and $\mathbf{1 b}$, instantaneous formation of a carbene complex apparently took place upon treatment with the cyclic olefins, similar to the recently described reaction of a non-carbene ligand-containing ruthenium(II) complex with norbornene [54]. For heterogeneous $\operatorname{Re}_{2} \mathrm{O}_{7} / \mathrm{Al}_{2} \mathrm{O}_{3}$ systems and some rhenium complexes in high oxidation state, there is a similar situation. The initial carbene has been proposed to be formed from the olefin by the reaction with traces of oxygen, by $\mathrm{C}-\mathrm{H}$ activation or $\alpha-\mathrm{H}$ transfer [55] including an alternative mechanism, which has been proposed recently [48b]. The observed relatively high polydispersity indices of the formed polymers (up to 3.626) pointed to either a very slow initiation mechanism followed by fast propagation steps or a non-single-site mechanism of the ROMP catalysis or of both.

Table 1 Polymerization of cyclic olefins at room temperature.

\begin{tabular}{llccccc}
\hline Initiator & Monomer & Yield $^{\mathrm{a}}$ & $10^{3} \times M_{\mathrm{n}}{ }^{\mathrm{b}}$ & $\mathrm{PDI}^{\mathrm{c}}$ & $Z^{\mathrm{d}}$ & $\mathrm{TOF}^{\mathrm{e}}$ \\
\hline $\mathbf{2 a}$ & norbornene & $>98 \%$ & 1396 & 3.945 & $85 \%$ & $\sim 650$ \\
$\mathbf{2 b}$ & norbornene & $>99 \%$ & 1418 & 2.238 & $85 \%$ & $\sim 700$ \\
$\mathbf{2 a}$ & DCPD* & $>97 \%$ & 1085 & 3.481 & - & $\sim 650$ \\
$\mathbf{2 b}$ & DCPD* & $>99 \%$ & 1492 & 3.626 & - & $\sim 700$ \\
$\mathbf{2 a}$ & cyclooctene & $\sim 20 \%$ & - & - & $75 \%$ & $<100$ \\
$\mathbf{2 b}$ & cyclooctene & $\sim 23 \%$ & 2191 & 1.894 & $75 \%$ & $<100$ \\
\hline
\end{tabular}

aPolymerization reactions with norbornene and DCPD were quenched with methanol after $1 \mathrm{~h}$; polymerizations of cyclooctene were quenched after $2 \mathrm{~h}$.

betermined by GPC in THF vs. polystyrene standards at CIBA Specialty Chemicals in Basel.

'Polydispersity index $M_{\mathrm{w}} / M_{\mathrm{n}}$ determined at CIBA Specialty Chemicals in Basel.

${ }^{\mathrm{d}}$ Determined by ${ }^{1} \mathrm{H}$ and ${ }^{13} \mathrm{C}$ NMR.

${ }^{\mathrm{e}}$ Turnover frequency in moles of olefin converted per mole of catalyst per hour. *DCPD = dicyclopentadiene. 
Thus, $\mathbf{1 a}$ and $\mathbf{1 b}$ are suitable catalysts only for ROMP of strained and non-heterofunctionalized cyclic olefins. Various acyclic olefins (e.g., 1-hexene, ethyl vinyl ether) did not undergo olefin metathesis in the presence of these complexes.

\section{Initiation and propagation of the ROMP reaction of $1 \mathrm{a}$ and $1 \mathrm{~b}$ with norbornene}

In order to achieve deeper mechanistic insight into the catalytic ROMP reactions, an exploratory ${ }^{1} \mathrm{H}$ NMR study was first carried out, adding norbornene to chlorobenzene solutions of 1a. Several very weak $\mathrm{H}_{\text {carbene }}$ resonances appeared $(14.62,13.84$, and $12.18 \mathrm{ppm})$ in a chemical shift range typical for transition-metal carbene complexes. A peculiar and novel initiation mechanism of the catalytic reaction, which can not be accessed with acyclic olefins, is therefore anticipated. In addition, functionalized cyclic olefins like bicyclo[2.2.1]-5-heptene-2,3-dicarboxylate or 5-norbornene-2-carbonitrile were also not observed to undergo ROMP presumably due to their too tight coordination at vacant sites. This indeed stresses the presence of vacant sites during catalysis, in particular in the initiation pathway. Furthermore, in agreement with this observation, the addition of an equimolar amount of free phosphine or acetonitrile to chlorobenzene solutions of norbornene and $\mathbf{1}$ resulted in a dramatic decrease of their catalytic activity.

According to Scheme 3, 1a and $\mathbf{1 b}$ were expected to generate a carbene complex from norbornene via 3a,b. In a next step, phosphine migration should take place to yield the phosphonio complexes $\mathbf{4 a}, \mathbf{b}$. This species could undergo cleavage of the resulting phosphonio norbonyl $\mathrm{C}-\mathrm{C}$ bond, producing in a step-wise fashion the carbene ylid complexes $\mathbf{5 a}, \mathbf{b}$ first or could directly be transformed to the ylid intermediates $\mathbf{6 a}, \mathbf{b}$.

The $\mathrm{C}_{\text {ylid }}$ complexes $\mathbf{6 a}$, $\mathbf{b}$ could react further with norbornene to the rhenacyclobutanes of type 7a,b. Subsequent nucleophilic attack of the ylid function on a NO ligand would lead to $\mathbf{8 a}, \mathbf{b}$. Elimination of phosphine oxide yields the intermediates 9a,b the crucial species to feed the ROMP propagation cycle, thus closing up the initiation part of the ROMP pathway. The described sequence of reaction steps is supported by the observation that thermal treatment of chlorobenzene solutions of $\mathbf{2 a}, \mathbf{b}$ result in phosphine migration onto their coordinated carbene ligands affording the quite stable ylid complexes $\left[\operatorname{Re}\left\{\mathrm{CH}\left(\mathrm{C}_{6} \mathrm{H}_{5}\right)\left(\mathrm{PR}_{3}\right)\right\}(\mathrm{NO})_{2}\left(\mathrm{PR}_{3}\right)\right]\left[\mathrm{BAr}{ }_{4}\right](\mathbf{1 3 a}, \mathbf{b})$ structurally related to $\mathbf{6 a}, \mathbf{b}$ (see Fig. 1). Complexes 13a,b were fully characterized by various NMR techniques and an X-ray diffraction study of 13a [53].

For the propagation cycle, principally three parallel olefin metathesis routes were envisaged to drive the ROMP metathesis cycle. They are denoted as the "ylid", the " $C$-nitroso", and the "iminate" routes (see Scheme 3). Depending on the thermodynamics following $7 \mathbf{a}, \mathbf{b} \rightarrow \mathbf{8 a}, \mathbf{b} \rightarrow \mathbf{9 a}, \mathbf{b}$, these pathways could appear as parallel routes which would be in agreement with the observation of the high polydispersity index of the polymers. Starting from these species, alternating rhenacyclobutane and carbene formations would lead to increasing ring sizes of the rhenacycles and polymerization. Species $\mathbf{6 a}, \mathbf{b}$ and 7a,b of the initiation part are related to the "ylid" route, but via attack of the ylid function on the NO group and elimination of ${ }^{i} \mathrm{Pr}_{3} \mathrm{P}=\mathrm{O}$ or $\mathrm{Cy}_{3} \mathrm{P}=\mathrm{O}$, the " $C$-nitroso" and the "iminate" routes could subsequently be entered. In norbornene ROMP experiments, the phosphine oxide formation was confirmed by NMR spectroscopy using concentrated chlorobenzene solutions of $\mathbf{1 a}, \mathbf{b}$. 


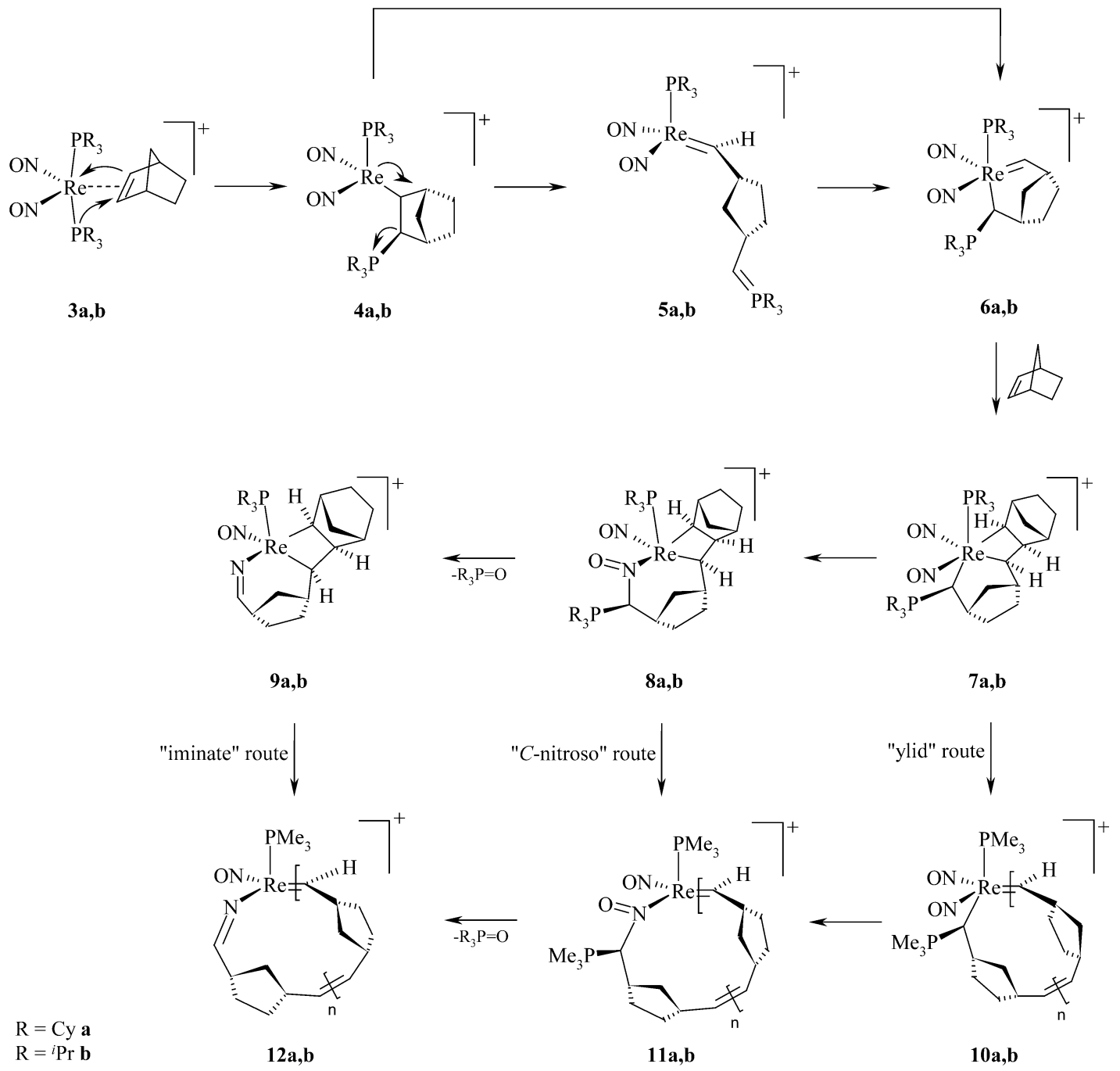

Scheme 3

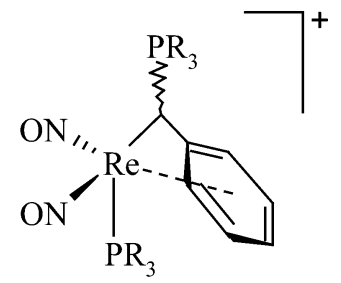

13a,b

$\mathrm{R}=\mathrm{Cy} \mathbf{a} ;{ }^{i} \operatorname{Pr} \mathbf{b}$

Fig. 1 


\section{DFT studies on ROMP with the $\left[\operatorname{Re}(\mathrm{NO})_{2}\left(\mathrm{PMe}_{3}\right)_{2}\right]^{+}$cation}

Since the ROMP mechanisms of complexes $\mathbf{1 a}$ and $\mathbf{1 b}$ could not be fully established on an experimental base, supporting density functional theory (DFT) computational studies were carried out with structural optimization of potential model intermediates of the ROMP catalysis with norbornene. The complete DFT analysis has been published recently [53]. The DFT calculations were carried out using $\mathrm{PMe}_{3}$ ligands, and the relative energies are referenced to the total energy of the norbornene complex 3-Me with an orientation of the olefin perpendicular to the Re-P axis. The rotamer with a parallel orientation is $4.2 \mathrm{kcal} / \mathrm{mol}$ higher in energy. A phosphine migration in 3-Me yielding in the phosphonio norbonyl complex 4-Me was calculated to be $12.3 \mathrm{kcal} / \mathrm{mol}$ higher in energy than 3-Me. The optimized structure of 4-Me shows considerable lengthening of the activated olefinic $\mathrm{C}-\mathrm{C}_{\text {norb }}$ bond expanding from 1.408 $\AA$ in 3-Me to $1.570 \AA$, thus preparing for $\mathrm{C}-\mathrm{C}$ bond rupture. The cleavage of the olefinic $\mathrm{C}-\mathrm{C}_{\text {norb }}$ bond in 4-Me results in an ylid carbene complex (5-Me) with a pending ylid function, which successively would coordinate to generate 6-Me. However, a transition state might form, avoiding loss of rhenium contact of the migrating $\mathrm{C}_{\text {norbornene }}$ atom, yielding 6-Me directly. The optimized structure of 6-Me has a computed energy of $+31.5 \mathrm{kcal} / \mathrm{mol}$ relative to 3-Me. Nucleophilic attack of the ylid ligand of 6-Me onto one of the nitrosyl groups to reach a four-coordinated $C$-nitroso species is energetically uphill by additional $9.3 \mathrm{kcal} / \mathrm{mol}$. In real catalytic systems, this route seems unfavorable, since the competing norbornene addition of 6-Me to give 7-Me is, in contrast to the nucleophilic attack onto the NO ligand, slightly exothermic $(-5.2 \mathrm{kcal} / \mathrm{mol})$. The opening of the rhenacyclobutane yields in 10-Me, which is endothermic by $5.9 \mathrm{kcal} / \mathrm{mol}$. Subsequent dissociation of the $\mathrm{PMe}_{3}$ ligand would increase the energy for the corresponding structure by additional $+15.5 \mathrm{kcal} / \mathrm{mol}$ and thus cannot easily be achieved in real catalytic cycles at room temperature.

Depending on the activation barrier of the step 7-Me $\rightarrow$ 10-Me, the "ylid" route (see 7-Me $\rightarrow$ 10-Me $\rightarrow$ 16-Me $\rightarrow$ 17-Me in Scheme 4) might be followed in real catalytic pathways for a few such steps. However, the high thermodynamic levels of these species are expected to undergo intramolecular NO ligand attack yielding in " $C$-nitroso" species related to 8-Me and 11-Me. The activation barrier of these steps is not known and leaves open at which step the NO attack occurs along the initial "ylid" route. However, the DFT analysis allows us to conclude that this merge to form a $C$-nitroso complex could not occur with $\mathbf{6 a}, \mathbf{b}$. The formed ylid rhenacycle is too highly strained in the rhenacycle and therefore thermodynamically inaccessible. The " $C$-nitroso" route 8 -Me $\rightarrow$ 11-Me $\rightarrow$ 18-Me $\rightarrow$ 19-Me (Scheme 4) is also not realized in the real catalytic cycles, since the competing formation of the iminate complexes 9-Me, 12-Me, 14-Me, and 15-Me are clearly favored by 32.4, 40.6, 38.3, and $48.9 \mathrm{kcal} / \mathrm{mol}$, respectively, over the corresponding " $C$-nitroso" species. The huge exothermic reactions are caused by $\mathrm{Me}_{3} \mathrm{P}=\mathrm{O}$ formation. This makes the "iminate" route a thermodynamic sink, and most probable to be accessed in real catalytic cycles. The relatively large thermodynamic gain of approximately $-21 \mathrm{kcal} / \mathrm{mol}$ in the "iminate" route presumably fully expresses the release of ring strain from the norbornene unit without "compensation" by strain contributions of the iminate ring. In conclusion, the thermodynamic evaluations suggest that ROMP of norbornene occurs mainly along the "iminate" route. 


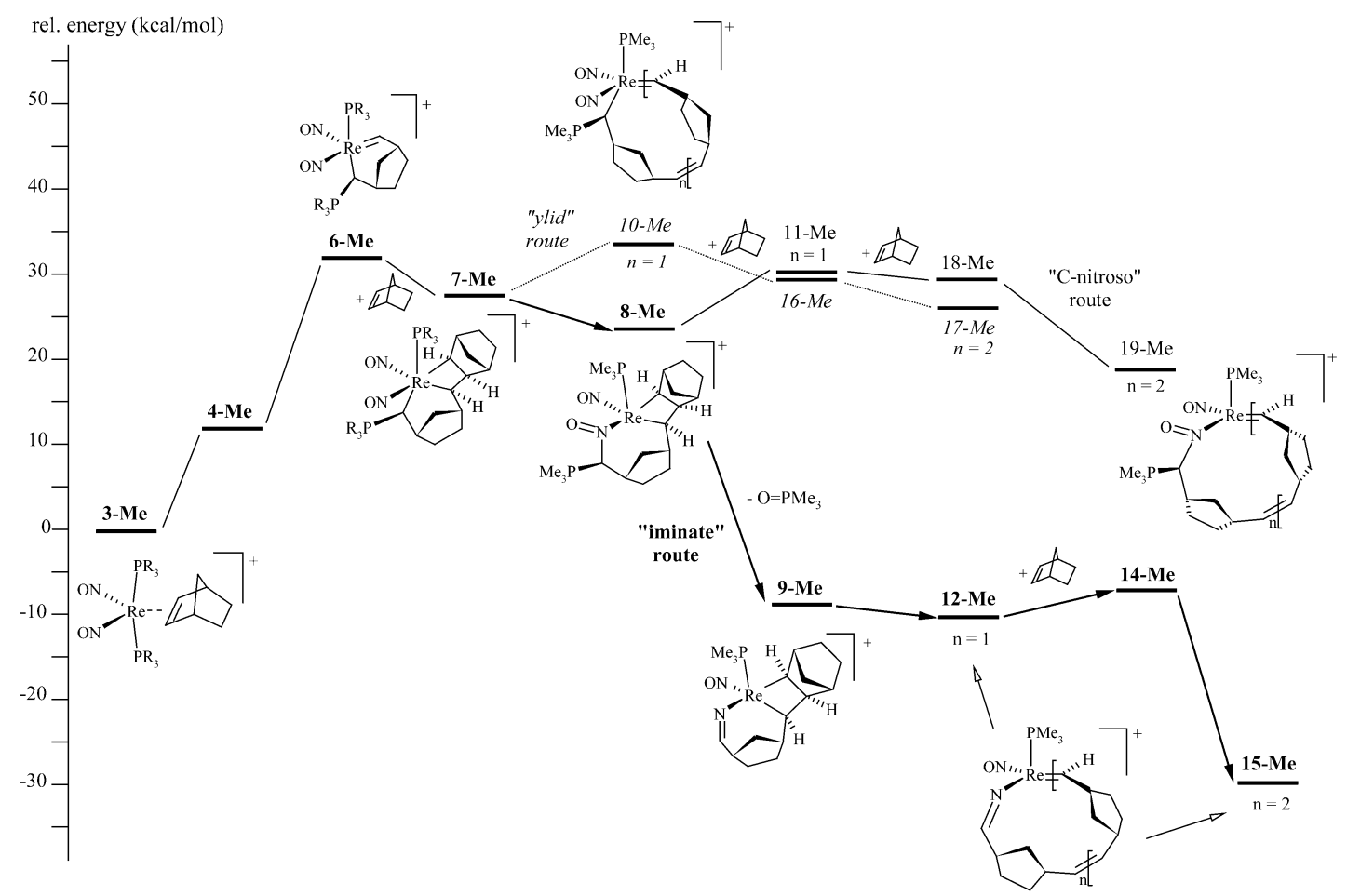

Scheme 4 The "iminate" (bold), "ylid" (italic) and "C-nitroso" propagation routes of the ROMP of norbornene with various chemically relevant and structurally optimized model intermediates.

\section{CONCLUSION}

Catalytic ROMP activity of the cationic low-valent rhenium dinitrosyl bisphosphine complexes was observed. This reactivity was unexpected, since none of their ligands can be envisaged to be converted into a carbene unit. It could be shown that the formation of a carbene ligand is accomplished in situ from the initially formed rhenium complexes with highly strained, nonfunctionalized cyclic olefins, like norbornene. The carbene formation as the initiation step does not take place using functionalized cyclic olefins like bicyclo[2.2.1]-5-heptene-2,3-dicarboxylate or 5-norbornene-2-carbonitrile. The presented mechanism is supported by experimental and theoretical studies involving the cleavage of the strained olefinic bond by phosphine migration, forming ylid carbene complexes. The formed ylid function attacks a nitrosyl ligand, which leads in a Wittig-type reaction to elimination of phosphine oxide as a key step providing a thermodynamic driving force for the initial reaction course. The initial "ylid route" thus merges into the "iminate route" along which carbene species are assumed to be provided to drive the ROMP propagation and the total polymerization process by alternating rhenacyclobutane formations and cycloreversions according to Scheme 1.

\section{REFERENCES}

1. K. J. Ivin, J. C. Mol. In Olefin Metathesis and Metathesis Polymerization, K. J. Ivin, J. C. Mol (Eds.), Academic Press, San Diego (1997).

2. F. Zaragoza Dörwald. In Metal Carbenes in Organic Synthesis, Wiley-VCH, Weinheim (1999).

3. (a) A. Füstner. Angew. Chem. 112, 3140 (2000); (b) A. Füstner. Angew. Chem., Int. Ed. 39, 3012 (2000). 
4. T. M. Trnka, R. H. Grubbs. Acc. Chem. Res. 34, 18 (2001).

5. (a) H. S. Eleuterio. U.S. Patent 3074918 (1963); (b) H. S. Eleuterio. J. Mol. Catal. 65, 55 (1991); (c) In fact, there is earlier evidence for the discovery of the metathesis reaction in polymer chemistry (ROMP) from A. W. Anderson, N. G. Merckling. U.S. Patent 2721189 (1955); (d) For a comprehensive review: K. J. Ivin, J. C. Mol. In Olefin Metathesis and Metathesis Polymerization, K. J. Ivin, J. C. Mol (Eds.), Academic Press, San Diego (1997).

6. N. Calderon, H. Y. Chen, R. W. Scott. Tetrahedron Lett. 8, 3327 (1967).

7. N. Calderon, E. A. Ofstead, J. P. Ward, W. A. Judy, K. W. Scott. J. Am. Chem. Soc. 90, 4133 (1968).

8. J. L. Wang, H. R. Menapace. J. Org. Chem. 33, 3794 (1968).

9. E. A. Zuech, W. B. Hughes, D. H. Kubicek, E. T. Kittelman. J. Am. Chem. Soc. 92, 528 (1970).

10. (a) E. Verkuijlen, F. Kapteijn, J. C. Mol, C. Boelhouwer. J. Chem. Soc., Chem. Commun. 198 (1977); (b) S. Sibeijn, J. C. Mol. Appl. Catal. 67, 279 (1991); (c) J. C. Mol. Green Chem. 4, 5 (2002).

11. J. A. Moulijn, C. Boelhouwer. Chem. Commun. 1170 (1971).

12. (a) E. T. Kittleman, E. A. Zuech. French Patent 1561025 (1967); (b) E. T. Kittleman, E. A. Zuech. Chem. Abstr. 72, 31193 (1970).

13. Y. Uchida, M. Hidai, T. Tatsumi. Bull. Chem. Soc. Jpn. 45, 1158 (1972).

14. W. A. Herrmann. J. Organomet. Chem. 500, 149 (1995).

15. C. C. Romao, F. E. Kühn, W. A. Herrmann. Chem. Rev. 97, 3197 (1997).

16. L. J. Morris, A. J. Downs, T. M. Greene, G. S. McGrady, W. A. Herrmann, P. Sirsch, W. Schere, O. Gropen. Organometallics 20, 2344 (2001).

17. (a) M. Yamaguchi, Y. Tsunoda. Japanese Patent 07124 (1974); (b) M. Yamaguchi, Y. Tsunoda. Chem. Abstr. 80, 132758 (1974).

18. W. R. Kroll, G. Doyle. J. Catal. 24, 356 (1972).

19. M. F. Farona, W. S. Greenlee. J. Chem. Soc., Chem. Commun. 759 (1975).

20. Commercial aspects of olefin metathesis are reviewed in the following: K. J. Ivin, J. C. Mol. Olefin Metathesis and Metathesis Polymerization, Academic Press, New York (1997).

21. (a) B. L. Goodall, W. J. Kroenke, R. J. Minchak, L. F. Rhodes. J. Appl. Polym. Sci. 47, 607 (1993); (b) M. McCann, D. McDonnell, B. L. Goodall. J. Mol. Catal. A 96, 31 (1995); (c) L. F. Rhodes. European Patent 0435146 A2 (1990); (d) A. M. Mazany. European Patent 0755938 A1, 118, 100 (1995); (e) M. Ulman, R. H. Grubbs. Organometallics 17, 2484 (1998).

22. S. T. Nguyen, L. K. Johnson, R. H. Grubbs, J. W. Ziller. J. Am. Chem. Soc. 114, 3974 (1992).

23. P. Schwab, R. H. Grubbs, J. W. Ziller. J. Am. Chem. Soc. 118, 100 (1996).

24. R. H. Grubbs, S. J. Miller, G. C. Fu. Acc. Chem. Res. 28, 446 (1995).

25. Reviews on NHC: (a) W. A. Herrmann, C. Köher. Angew. Chem. 109, 2256 (1997); (b) W. A. Herrmann, C. Köher. Angew. Chem., Int. Ed. 36, 2162 (1997); (c) A. J. Arduengo. Acc. Chem. Res. 32, 913 (1999).

26. (a) M. Scholl, T. M. Trnka, J. P. Morgan, R. H. Grubbs. Tetrahedron Lett. 40, 2247 (1999); (b) M. Scholl, S. Ding, W. C. Lee, R. H. Grubbs. Org. Lett. 1, 953 (1999).

27. (a) J. Huang, E. D. Stevens, S. P. Nolan, J. L. Petersen. J. Am. Chem. Soc. 121, 2674 (1999); (b) J. Huang, H.-J. Schanz, S. P. Nolan. Organometallics 18, 5375 (1999).

28. (a) T. Weskamp, F. J. Kohl, W. Hieringer, D. Gleich, W. A. Herrmann. Angew. Chem. 111, 2573 (1999); (b) T. Weskamp, F. J. Kohl, W. Hieringer, D. Gleich, W. A. Herrmann. Angew. Chem., Int. Ed. 38, 2416 (1999); (c) L. Ackermann, A. Füstner, T. Weskamp, F. J. Kohl, W. A. Herrmann. Tetrahedron Lett. 40, 4787 (1999); (d) T. Weskamp, F. J. Kohl, W. A. Herrmann. J. Organomet. Chem. 582, 362 (1999). 
29. (a) R. R. Schrock, J. S. Murdzek, G. C. Bazan, J. Robbins, J. Dimare, M. B. O'Regan. J. Am. Chem. Soc. 112, 3875 (1990); (b) G. C. Bazan, E. Khosravi, R. R. Schrock, W. J. Feast, V. C. Gibson, M. B. O'Regan, J. K. Thomas, W. M. Davis. J. Am. Chem. Soc. 112, 8378 (1990); (c) G. C. Bazan, H. Oskam, H. N. Cho, L. Y. Park, R. R. Schrock. J. Am. Chem. Soc. 113, 6899 (1991).

30. (a) S. M. Hansen, F. Rominger, M. Metz, P. Hofmann. Chem. Eur. J. 5, 557 (1999); (b) S. M. Hansen, M. A. O. Volland, F. Rominger, F. Eisenträger, P. Hofmann. Angew. Chem. 111, 1360 (1999); (c) S. M. Hansen, M. A. O. Volland, F. Rominger, F. Eisenträger, P. Hofmann. Angew. Chem., Int. Ed. 38, 1273 (1999); (d) P. Hofmann, M. A. O. Volland, S. M. Hansen, F. Eisenträger, J. H. Gross, K. Stengel. J. Organomet. Chem. 606, 88 (2000).

31. P. E. Romero, W. E. Piers, R. McDonald. Angew. Chem., Int. Ed. 43, 6161 (2004).

32. J.-L. Hérisson, Y. Chauvin. Makromol. Chem. 141, 161 (1970).

33. E. L. Dias, S. T. Nguyen, R. H. Grubbs. J. Am. Chem. Soc. 119, 3887 (1997).

34. M. Ulman, R. H. Grubbs. Organometallics 17, 2484 (1998).

35. M. Ulman, R. H. Grubbs. J. Org. Chem. 64, 7202 (1999).

36. M. S. Sanford, M. Ulman, R. H. Grubbs. J. Am. Chem. Soc. 123, 749 (2001).

37. M. S. Sanford, J. A. Love, R. H. Grubbs. J. Am. Chem. Soc. 123, 6543 (2001).

38. (a) C. Hinderling, C. Adlhart, P. Chen. Angew. Chem. 110, 2831 (1998); (b) C. Hinderling, C. Adlhart, P. Chen. Angew. Chem., Int. Ed. 37, 2685 (1998).

39. C. Adlhart, C. Hinderling, H. Baumann, P. Chen. J. Am. Chem. Soc. 122, 8204 (2000).

40. C. Adlhart, M. A. O. Volland, P. Hofmann, P. Chen. Helv. Chim. Acta 83, 3306 (2000).

41. M. A. O. Volland, C. Adlhart, C. A. Kiener, P. Chen, P. Hofmann. Chem. Eur. J. 7, 4621 (2001).

42. J. A. Tallarico, P. J. Bonitatebus Jr., M. L. Snapper. J. Am. Chem. Soc. 119, 7157 (1997).

43. (a) M. S. Sanford, L. M. Henling, M. W. Day, R. H. Grubbs. Angew. Chem. 112, 3593 (2000); (b) M. S. Sanford, L. M. Henling, M. W. Day, R. H. Grubbs. Angew. Chem., Int. Ed. 39, 3451 (2000).

44. (a) M. T. Reetz, M. H. Becker, M. Liebl, A. Fürstner. Angew. Chem. 112, 1294 (2000); (b) M. T. Reetz, M. H. Becker, M. Liebl, A. Fürstner. Angew. Chem., Int. Ed. 39, 1236 (2000).

45. A. Fürstner, L. Ackermann, B. Gabor, R. Goddard, C. W. Lehmann, R. Mynott, F. Stelzer, O. R. Thiel. Chem. Eur. J. 7, 3236 (2001).

46. (a) F. Kapteijn, H. L. G. Bredt, E. Homburg, J. C. Mol. Ind. Eng. Chem. Prod. Res. Dev. 20, 457 (1981); (b) J. Chauvin, D. Commereuc. J. Chem. Soc., Chem. Commun. 462 (1992).

47. J. C. Mol. Catal. Today 51, 289 (1999).

48. X. Chen, X. Zhang, P. Chen. Angew. Chem., Int. Ed. 42, 3798 (2003).

49. (a) W. A. Herrmann. J. Organomet. Chem. 500, 149 (1995); (b) C. C. Romao, F. E. Kühn, W. A. Herrmann. Chem. Rev. 97, 3197 (1997); (c) R. R. Schrock, R. T. Depue, J. Feldman, C. J. Schaverien, J. C. Dewan, A. H. Liu. J. Am. Chem. Soc. 110, 1423 (1988); (d) M. H. Schofield, R. R. Schrock, L. Y. Park. Organometallics 10, 1844 (1991); (e) A. Weinstock, R. R. Schrock, W. M. Davis. J. Am. Chem. Soc. 113, 135 (1991); (f) R. Toreki, R. R. Schrock. J. Am. Chem. Soc. 112, 2448 (1990); (g) R. Toreki, R. R. Schrock. J. Am. Chem. Soc. 114, 3367 (1992); (h) R. Toreki, G. A. Vaughan, R. R. Schrock, W. M. Davis. J. Am. Chem. Soc. 115, 127 (1993); (i) R. Toreki, R. R. Schrock, W. M. Davis. J. Organomet. Chem. 520, 69 (1996); (j) G. A. Vaughan, R. Toreki, R. R. Schrock, W. M. Davis. J. Am. Chem. Soc. 115, 2980 (1993); (k) A. M. LaPointe, R. R. Schrock. Organometallics 14, 1875 (1995).

50. (a) T. J. Katz, N. Acton. Tetrahedron Lett. 17, 4251 (1976); (b) M. Doherty, A. Siove, A. Parlier, H. Rudler, M. Fontanille. Makromol. Chem., Macromol. Symp. 6, 33 (1986); (c) S. Warwel, V. Siekermann. Makromol. Chem., Rapid Commun. 4, 423 (1983).

51. (a) H. Jacobsen, K. Heinze, A. Llamazares, H. Schmalle, G. Artus, H. Berke. J. Chem. Soc., Dalton Trans. 1717 (1999); (b) A. Llamazares, H. W. Schmalle, H. Berke. Organometallics 20, 5277 (2001); (c) D. G. Gusev, A. Llamazares, G. Artus, H. Jacobsen, H. Berke. Organometallics 18, 75 (1999). 
52. (a) E. A. Zuech. J. Chem. Soc., Chem. Commun. 1182 (1968); (b) E. A. Zuech, W. B. Hughes, D. H. Kubicek, E. T. Kittleman. J. Am. Chem. Soc. 92, 528 (1970); (c) R. Taube, K. Z. Seyferth. Z. Chem. 13, 300 (1977); (d) R. Taube, K. Seyferth. Z. Anorg. Allg. Chem. 437, 213 (1973); (e) M. Leconte, J.-M. Basset. J. Am. Chem. Soc. 101, 7296 (1979); (f) K. Seyferth, K. Rosenthal, G. Kühn, R. Taube. Z. Anorg. Allg. Chem. 513, 57 (1984); (g) K. Seyferth, R. Taube. J. Organomet. Chem. 262, 191 (1984); (h) A. Keller, L. Szterenberg. J. Mol. Catal. 57, 207 (1989); (i) A. Keller. J. Organomet. Chem. 407, 237 (1990); (j) A. Keller, L. Szterenberg. Z. Naturforsch., B: Condens. Matter 47, 1469 (1991); (k) A. Keller. J. Organomet. Chem. 436, 199 (1992); (l) A. Keller. J. Mol. Catal. 78, L15 (1993); (m) A. Keller, R. Matusiak. J. Mol. Catal. A 104, 213 (1996); (n) A. Keller, J. M. Sobczak, R. Matusiak. J. Mol. Catal. A 136, 115 (1998); (o) A. Keller, R. Matusiak. J. Mol. Catal. A 142, 317 (1999); (p) R. Matusiak, A. Keller. Polym. Bull. 43, 199 (1999).

53. C. M. Frech, O. Blaque, H. W. Schmalle, H. Berke, C. Adlhart, P. Chen. Chem. Eur. J. 12, 3325 (2006).

54. (a) J. M. E. Matos, B. S. Lima-Neto. J. Mol. Catal. A 222, 81 (2004); (b) N. Cobo, M. A. Esteruelas, F. Gonzalez, J. Herrero, A. M. Lopez, P. Lucio, M. Olivan. J. Catal. 223, 319 (2004); (c) L. Bencze, N. Biro, B. Szabo-Ravasz, L. Mihichuk. Can. J. Chem. 82, 499 (2004).

55. (a) K. J. Ivin, B. S. R. Reddy, J. J. Rooney. J. Chem. Soc., Chem. Commun. 1062 (1981); (b) G. J. Spivak, J. N. Coalter. Organometallics 17, 999 (1998); (c) J. N. Coalter, G. J. Spivak, H. Gérard, E. Clot, E. R. Davidson, O. Eisenstein, K. C. Caulton. J. Am. Chem. Soc. 120, 9388 (1998); (d) J. N. Coalter, J. C. Bollinger, O. Eisenstein, K. G. Caulton. New J. Chem. 24, 925 (2000); (e) G. Ferrando-Miguel, J. N. Coalter, H. Gerard, J. C. Huffman, O. Eisenstein, K. G. Caulton. New J. Chem. 26, 687 (2002); (f) G. Ferrando, H. Gerard, G. J. Spivak, J. N. Coalter, J. C. Huffman, O. Eisenstein, K. G. Caulton. Inorg. Chem. 40, 6610 (2001); (g) J. N. Coalter, J. C. Bollinger, J. C. Huffman, U. Werner-Zwanziger, K. G. Caulton, E. R. Davidson, E. Clot, O. Eisenstein. New J. Chem. 24, 9 (2000); (h) N. Dolker, G. Frenking. J. Organomet. Chem. 617, 225 (2001). 